\title{
Combined use of modified Alvarado score and USG in decreasing negative appendicectomy rate
}

\author{
Hemant Nautiyal $\cdot$ Shabi Ahmad $\cdot$ N. K. Keshwani $\cdot$ D. N. Awasthi
}

Received: 25 October 2008 / Accepted: 29 July 2009

(C) Association of Surgeons of India 2009

\begin{abstract}
Introduction Appendicitis is notorious in its ability to simulate other conditions and in the frequency it can be mimicked by other pathologies. Despite extraordinary advances in modern radiography imaging and diagnostic laboratory investigations the accurate diagnosis of acute appendicitis remains an enigmatic challenge. Of the various commonly used diagnostic aids for appendicitis, no single test can reduce the rate of negative appendicectomy to zero.
\end{abstract}

Materials and methods Fifty admitted cases of suspected appendicitis were subjected to ultrasonography (USG). All the patients were scored out of 9 according to modified Alvarado score. A treatment plan was devised according to which patients with modified Alvarado score $\geq 7$ underwent immediate appendicectomy even if USG was negative for appendicitis and patients with score $<7$ underwent appendicectomy if USG was positive for appendicitis.

Result $\quad 84.3 \%$ of males and $44.4 \%$ of females admitted as case of suspected appendicitis had confirmed appendicitis. Due to high sensitivity $(97.14 \%)$ and accuracy $(92 \%)$ of our diagnostic approach, $85.71 \%$ cases of appendicitis were diagnosed in early stage, with only $8.57 \%$ perforation and abscess rate, leading to post appendicectomy complication rate of only $5.14 \%$ in our study (one wound infection and

H. Nautiyal · S. Ahmad · N. K. Keshwani · D. N. Awasthi Department of General Surgery,

Motilal Nehru Medical College, Allahabad, Uttar Pradesh, India

H. Nautiyal $(\bowtie)$

E-mail: drnauty1@rediffmail.com one urinary retention). We could achieve low negative appendicectomy rate of $7.14 \%$ in males and $11.11 \%$ in females and overall $8.11 \%$ in our study.

Conclusion Combined use of modified Alvarado score and high frequency USG not only reduces negative appendicectomy rate but also reduces morbidity and postoperative complications.

Keywords Ultrasonography $\cdot$ Acute appendicitis $\cdot$ Alvarado scores

\section{Introduction}

It has been over 100 years since Fitz presented his classic paper describing the clinical features of appendicitis and recommended early surgical removal of the inflamed appendix [1]. Appendicitis is notorious in its ability to simulate other conditions and in the frequency it can be mimicked by other pathologies.

Despite extraordinary advances in modern radiography imaging and diagnostic laboratory investigations the accurate preoperative diagnosis of acute appendicitis remains an enigmatic challenge. Overall, a negative appendicectomy rate of approximately $20 \%$ is commonly reported [2-9]. Nowadays commonly used diagnostic aids for appendicitis are CECT abdomen, laparoscopy, diagnostic scores, USG. By using diagnostic aids for acute appendicitis, prolonged observation, negative appendicectomy and incidence of perforation can be reduced dramatically resulting in decreased financial cost of the systems employed. But no test can reduce the rate of negative appendicectomy to zero, hence some authors have recommended a combination of two or more investigations to increase accuracy even more. 


\section{Aim of study}

To evaluate combined use of modified Alvarado score and USG in decreasing negative appendicectomy rate.

\section{Materials and methods}

This study was carried out in Motilal Nehru Medical College and associated hospitals, during January 2003 to April 2004, on admitted patients of right lower quadrant pain suspected of appendicitis. Evaluation of patient was done by comprehensive history, clinicopathological examination, investigations and modified Alvarado score.

\section{Alvarado score (Table 1)}

This scoring system as described by Alvarado is based on three symptoms, three signs, two laboratory findings [10].

In this study we used slightly modified version of the Alvarado score by excluding one laboratory finding; shift to left of neutrophil maturation as this was not available from our laboratory on emergency basis, therefore, our patients were scored out of 9 rather 10 points.

The laboratory finding of leucocytosis is defined as Total Leucocyte count (TLC) to excess of $10 \times 10^{9}$ per litre (used in our study to asses Alvarado score).

Temperature Oral temperature $>37.3^{\circ}$ was considered positive.

Table 1 Alvarado score

\begin{tabular}{llc}
\hline & & Score \\
\hline Symptoms & Migratory Right Lower & 1 \\
& Quadrant (RLQ) pain & \\
& Anorexia & 1 \\
& Nausea/vomiting & 1 \\
Signs & Tenderness RLQ & 2 \\
& Rebound tenderness & 1 \\
& Elevated temperature & 1 \\
Laboratory & Leucocytosis & 2 \\
& Shift to left & 1 \\
\hline Total score & & 10 \\
\hline
\end{tabular}

Table 2 Plan of treatment

\begin{tabular}{lll}
\hline $\begin{array}{l}\text { Modified } \\
\text { Alvarado score }\end{array}$ & USG & Treatment plan \\
\hline$<7$ & Negative & Conservative \\
$<7$ & Positive & Appendicectomy \\
$\geq 7$ & Negative & Appendicectomy \\
$\geq 7$ & Positive & Appendicectomy \\
\hline
\end{tabular}

Ultrasonography (USG): USG of every patient was performed with $5 \mathrm{MHz}$ or $7.5 \mathrm{MHz}$ linear array transducer to diagnose appendicitis and with $3.5 \mathrm{MHz}$ convex transducer to rule out any other abdominal pathology. USG

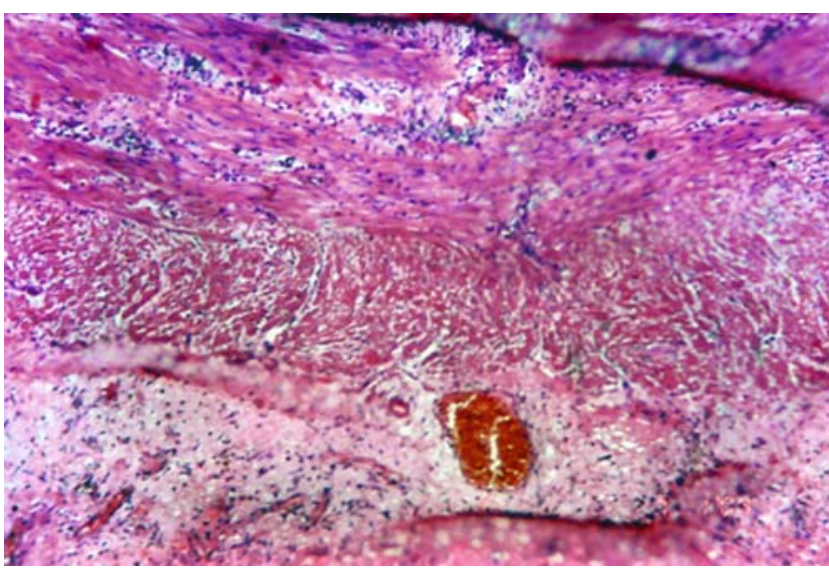

Fig. 1 Histological section of acute appendicitis showing congestion and inflammation in muscularis propria Hematoxylin and Eosin stain $(\mathrm{HE})(\times 100)$

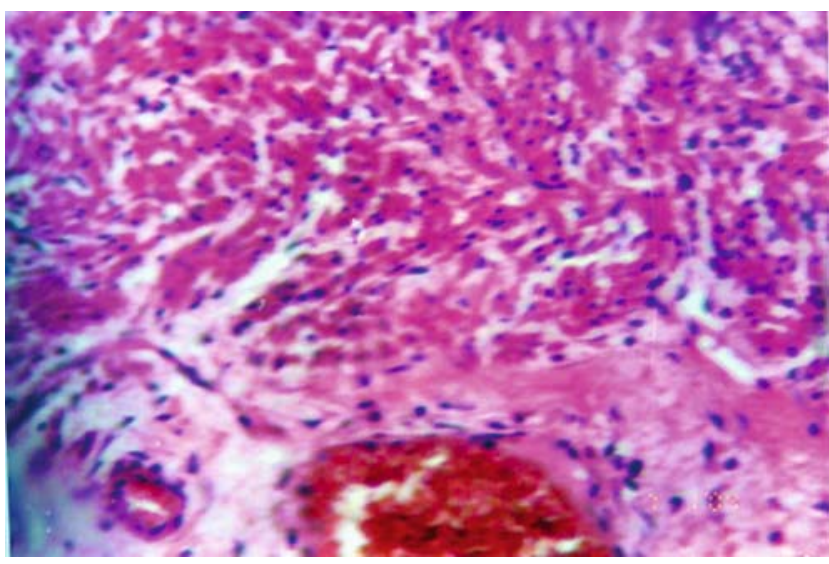

Fig. 2 High power view of the above section showing neutrophilic infiltration in muscularis propria $\mathrm{HE}(\times 400)$

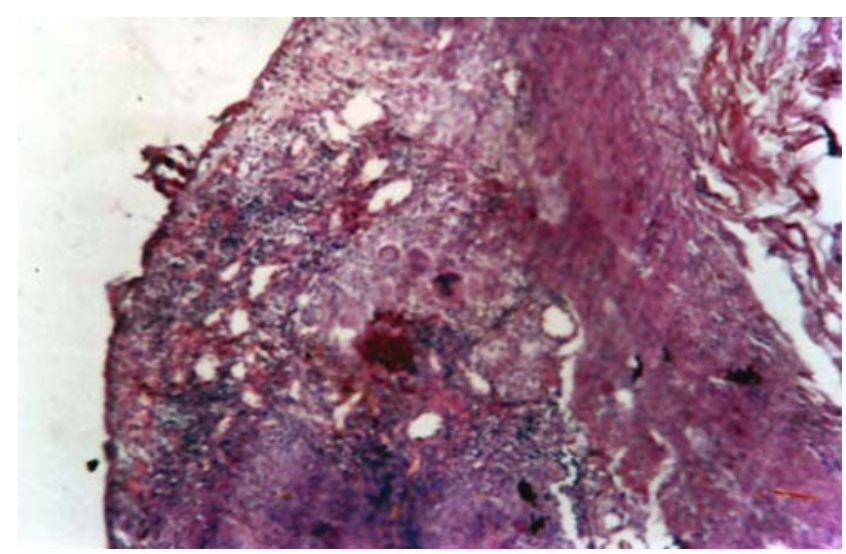

Fig. 3 One of our patient had tubercular appendicitis Histological section showing Langhans giant cells in lamina propria H.E $(\times 100)$ 
criteria for diagnosis of acute appendicitis was maximum diameter $\geq 6 \mathrm{~mm}$, or wall thickness $\geq 3 \mathrm{~mm}$, or increased periappendicular echogenicity (Fig. 5).

\section{Plan of treatment (Table 2)}

Confirmation of diagnosis of acute appendicitis was done by histopathological examination of appendix in all operated cases ( Fig. 1,2,3,4).

\section{Discussion}

Patients undergoing appendicectomy on clinical judgement had a diagnostic accuracy of only 70-75\%, negative appendicectomy rate of $25 \%$ and $35-45 \%$ in males and females, respectively has been found in studies conducted by Jess et al. [6], Dunn et al. [7], Lewis et al. [5], Chang et al. [4], diagnostic accuracy much less than our study $(92 \%)$, and negative appendicectomy rate much more than our study, males $7.14 \%$ and in females $11.11 \%$ (Tables 3, 4a, 4b, 12).

Table 3 Agewise and male/female distribution of other pathologies presenting as acute appendicitis

\begin{tabular}{|c|c|c|c|c|c|c|c|c|c|c|c|c|c|c|}
\hline \multirow{2}{*}{ Diagnosis } & \multicolumn{2}{|c|}{$0-10$} & \multicolumn{2}{|c|}{$11-20$} & \multicolumn{2}{|c|}{$21-30$} & \multicolumn{2}{|c|}{$31-40$} & \multicolumn{2}{|c|}{$41-50$} & \multicolumn{2}{|c|}{$51-60$} & \multicolumn{2}{|c|}{ Total } \\
\hline & $\mathrm{M}$ & $\mathrm{F}$ & $\mathrm{M}$ & $\mathrm{F}$ & $\mathrm{M}$ & $\mathrm{F}$ & $\mathrm{M}$ & $\mathrm{F}$ & $\mathrm{M}$ & $\mathrm{F}$ & $\mathrm{M}$ & $\mathrm{F}$ & No. & $\%$ \\
\hline Acute mesenteric lymphadenitis & & & 2 & & 1 & 1 & & & & & & & 4 & 8 \\
\hline Abdominal tuberculosis & 1 & & & 3 & & & & & & & & & 4 & 8 \\
\hline Ovarian cyst & & & & 1 & & & & 1 & & & & & 2 & 4 \\
\hline Terminal ileitis & & & 1 & & & 1 & & & & & & & 2 & 4 \\
\hline Tuboovarian mass (cause TB) & & & & 1 & & & & & & & & & 1 & 2 \\
\hline Meckel's diverticulitis & & & & & & & 1 & & & & & & 1 & 2 \\
\hline Acute cholecysitis & & & & & & 1 & & & & & & & 1 & 2 \\
\hline Total & 1 & & 3 & 5 & 1 & 3 & 1 & 1 & & & & & $15 \dagger$ & \\
\hline
\end{tabular}

$\uparrow 15$ (15 out of total 50 patients admitted with suspected appendicitis)

Table 4a Result of our treatment plan

\begin{tabular}{l|c|cc|cc|cc}
\hline \multirow{2}{*}{ Sex } & \multirow{2}{*}{$\begin{array}{c}\text { Modified Alvarado } \\
\text { score } \geq 7\end{array}$} & \multicolumn{2}{|c|}{ USG Positive } & \multicolumn{2}{c|}{ Treatment plan } & \multicolumn{2}{c}{ Confirmed appendicitis } \\
\cline { 3 - 7 } & 10 & No. & 7 & $(70)$ & $1 \dagger$ & 9 & No. \\
\hline Men & 3 & 2 & $(66.67)$ & - & 3 & $(\%)$ \\
Women & 2 & 2 & $(100)$ & - & 2 & 3 & $(100)$ \\
Children & 15 & 11 & $(73.3)$ & & & & $(100)$ \\
Total & & &
\end{tabular}

$\dagger$ Patient managed conservatively due to appendicular lump and later on underwent interval appendicectomy †One patient had Meckel's diverticulitis

Table 4b Results of our treatment plan

\begin{tabular}{l|c|cc|cc|cc}
\hline Sex & \multirow{2}{*}{$\begin{array}{c}\text { Modified Alvarado } \\
\text { score }<7\end{array}$} & \multicolumn{2}{|c|}{ USG positive } & \multicolumn{2}{c|}{ Treatment plan } & \multicolumn{2}{c}{ Confirmed appendicitis } \\
\cline { 3 - 7 } & & \multicolumn{2}{|c|}{ No. } & $(\%)$ & Conservative & Appendicectomy & No. \\
\hline Men & 19 & 16 & $(84.21)$ & $2 \dagger$ & $14 \dagger$ & $15+1 \#$ & $(93.75)$ \\
Women & 14 & 6 & $(42.86)$ & $2 \dagger$ & 4 & 5 & $(83.3)$ \\
Children & 2 & - & - & - & - & - \\
Total & 35 & 22 & $(62.85)$ & & & \\
\hline
\end{tabular}

†One negative appendicectomy

\#One appendicitis missed by USG with score $<7$, explored due to rising pulse rate

$\dagger$ Interval appendicectomy done later on 
Table 5 Sensitivity and specificity of our diagnostic approach in men

\begin{tabular}{l|cc|c}
\hline \multirow{2}{*}{ Diagnostic approach result } & \multicolumn{2}{|c|}{ Diagnosis } & \multirow{2}{*}{ Total } \\
\cline { 2 - 3 } & Appendicitis & Not appendicitis & \\
\hline Positive & (True positive) 24 & (False positive) 2 & 26 \\
Negative & (False negative) 1 & (True negative) 2 & 3 \\
Total & 25 & 4 & 29 \\
\hline
\end{tabular}

Sensitivity $=96 \%$; Predictive value of positive test $=92.31 \%$; Specificity $=50 \%$; Predictive value of negative test $=66.67 \% ;$ Accuracy $=89.66 \%$

Table 6 Sensitivity and specificity of our diagnostic approach in women

\begin{tabular}{l|cc|c}
\hline \multirow{2}{*}{ Diagnostic approach result } & \multicolumn{2}{|c|}{ Diagnosis } & \multirow{2}{*}{ Total } \\
\cline { 2 - 3 } & Appendicitis & Not appendicitis & 9 \\
Positive & (True positive) 8 & (False positive) 1 & 8 \\
Negative & (False negative) 0 & (True negative) 8 & 17 \\
Total & 8 & 9 & $17 \%$ \\
\hline
\end{tabular}

Sensitivity $=100 \%$; Predictive value of positive test $=88.89 \%$; Specificity $=88.89 \%$; Predictive value of negative test $=100 \%$; Accuracy $=94.12 \%$

Negative appendicectomy rate $=11.11 \%$

Table 7. Sensitivity and specificity of our diagnostic approach in children

\begin{tabular}{l|cc|c}
\hline \multirow{2}{*}{ Diagnostic Approach Result } & \multicolumn{2}{|c|}{ Diagnosis } & Total \\
\cline { 2 - 3 } & Appendicitis & Not Appendicitis & \\
\hline Positive & (True positive) & (False positive) & 2 \\
Negative & 2 & (True negative) & \\
Total & (False negative) & 2 & 2 \\
\hline
\end{tabular}

Sensitivity $=100 \%$, Predictive value of positive test $=100 \%$, Specificity $=100 \%$,

Predictive value of negative test $=100 \%$, Accuracy $=100 \%$

But it is not significant as sample size is small (Only 4 children)

Table 8 Overall sensitivity and specificity of our diagnostic approach

\begin{tabular}{l|cc|c}
\hline \multirow{2}{*}{ Diagnostic approach result } & \multicolumn{2}{|c|}{ Diagnosis } & \multirow{2}{*}{ Total } \\
\cline { 2 - 3 } & Appendicitis & Not appendicitis & 37 \\
Positive & (True positive) 34 & (False positive) 3 & 13 \\
Negative & (False negative) 1 & (True negative) 12 & 50 \\
\hline
\end{tabular}

Sensitivity $=97.14 \%$; Predictive value of positive test $=91.89 \%$; Specificity $=80 \%$; Predictive value of negative test $=92.31 \%$; Accuracy $=92 \%$

Table 9 Sensitivity and specificity of USG

\begin{tabular}{l|cc|c}
\hline \multirow{2}{*}{ Diagnostic approach result } & \multicolumn{2}{|c|}{ Diagnosis } & \multirow{2}{*}{ Total } \\
\cline { 2 - 3 } & Appendicitis & Not appendicitis & 33 \\
USG positive & (True positive) 31 & (False positive) 2 & 17 \\
USG negative & (False negative) 4 & (True negative) 13 & 50 \\
\hline
\end{tabular}

Negative appendicectomy rate (false positive rate) $=(2 / 33) 6.06 \%$; False negative rate $=(4 / 17) 23.53 \%$; Sensitivity $=88.57 \%$; Specificity $=86.67 \%$; Predictive value of positive test $=93.94 \%$; Predictive value of negative test $=76.47 \%$; Accuracy $=88 \%$ 
Clinical scoring systems devised by Teicher et al. [11], Alvarado [10], Lindberg and Fenyo [12], Ramirez and Dens [13], Galindo et al. [14] had sensitivity ranging from 48 to $77 \%$ while specificity of 73 to $87 \%$, which is less than sensitivity of our diagnostic approach $(97.14 \%)$ while specificity is nearly same (Tables $5,6,7,8$ )

In 1992, Owen et al. [15] used Alvarado score prospectively and found negative appendicectomy rate of $6 \%$ in men, $22 \%$ in women and $12 \%$ in children, with overall negative appendicectomy rate of $12.6 \%$. Kalan et al. [16] using modified version of Alvarado score found negative appendicectomy of $14.6 \%$, sensitivity of $93 \%$ in males and $67 \%$ in females. In a similar version of modified Alvarado score we had less negative appendicectomy rate as well as less sensitivity, but our diagnostic approach has less negative appendicectomy rate and more sensitivity (Tables 11, 12)
Studies conducted by using high frequency ultrasound in diagnosing appendicitis by Karstrup S et al. [17], Brooke et al. [18], Puylaert et al. [19], Yousef et al. [20], Schwerk et al. [21], David et al. [22], Wei-Ming kang et al. [23], Francois Vignault et al. [24], Riox [25], Crady et al. [26], John et al. [27] had sensitivity of 75-94\%, specificity of $73-100 \%$, predictive value of positive test $84-94.5 \%$, predictive value of negative test $89-96.3 \%$ and accuracy of $76-95.7 \%$. In all the above studies sensitivity is fairly less than our diagnostic approach (Table 8).

On comparing our diagnostic approach with our USG results (Table 10), our diagnostic approach is more sensitive (97.14\%) and more accurate (92\%). Though negative appendicectomy rate of USG in our study is low i.e. $6.06 \%$, but positive USG can not be a prerequisite for appendicectomy as there is high false negative rate of $23.53 \%$ (Table 9). It can only complement clinical scores or

Table 10 Results of modified Alvarado score

\begin{tabular}{lcc}
\hline & Modified Alvarado score $\geq 7$ & Confirmed appendicitis \\
\hline Men & $10($ FP, 10\%) & 9 \\
Women & 3 & 2 \\
Children & 2 & 14 \\
Total & Modified Alvarado score $<7$ & Confirmed appendicitis \\
\hline & 19 & $15+1 \uparrow=16$ \\
Men & 14 & 5 \\
Women & 2 & - \\
Total & 50 & 35 \\
\hline
\end{tabular}

†One case missed by even ultrasound (underwent exploratory laparotomy due to rising pulse rate)

Table 11 Sensitivity and specificity of modified Alvarado score

\begin{tabular}{l|cc|c}
\hline \multirow{2}{*}{ Diagnostic test result } & \multicolumn{2}{|c}{ Diagnosis } & \multirow{2}{*}{ Total } \\
\cline { 2 - 3 } & Appendicitis & Not appendicitis & 15 \\
Score $\geq 7$ positive & (True positive) 14 & (False positive) 1 & 35 \\
Score $<7$ negative & (False negative) 21 & (True negative) 14 & 50 \\
Total & 35 & 15 & \\
\hline
\end{tabular}

Negative appendicectomy rate (false positive rate) $=(1 / 15) 6.67 \%$; Sensitivity $=40 \%$; Specificity $=93.33 \%$; Predictive value of positive test $=93.33 \%$; Predictive value of negative test $=40 \%$; Accuracy $=56 \%$

Table 12 Negative appendicectomy rate of our diagnostic approach

\begin{tabular}{l|cc|cc}
\hline \multirow{2}{*}{$\begin{array}{l}\text { Appendicectomy d/t our } \\
\text { diagnostic approach }\end{array}$} & \multicolumn{2}{|c}{ Appendicitis on H/P Examination } & \multicolumn{2}{|c}{ Negative Appendicectomy } \\
\cline { 2 - 4 } & No. & $\%$ & No. & 7.14 \\
Male (28) & 26 & 92.86 & 1 & 11.11 \\
Female (9) & 8 & 88.89 & 3 & 8.11 \\
Total (37) & 34 & 91.89 & 2 & $\%$ \\
\hline
\end{tabular}

Overall negative appendicectomy rate $8.11 \%$ 


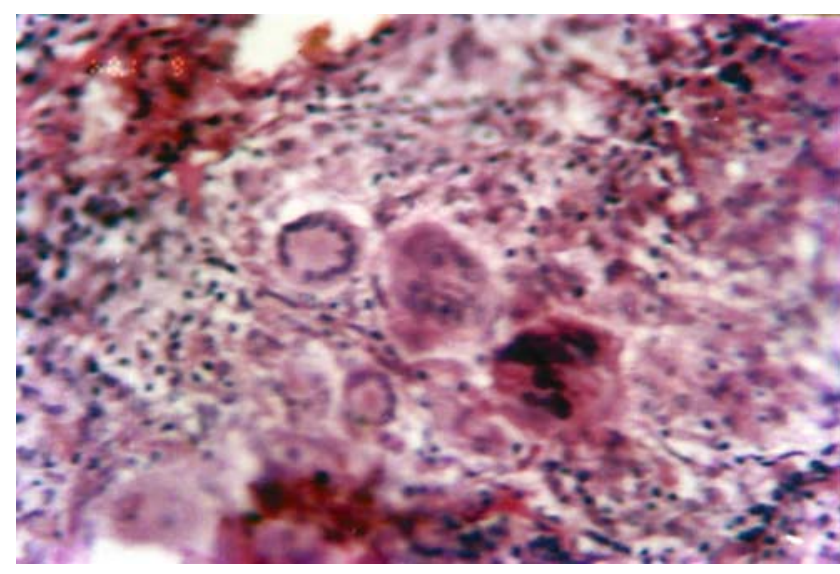

Fig. 4 High power view of tubercular appendicitis showing Langhans giant cells in lamina propria HE $(\times 400)$

Table 13 Pathological stages of acute appendicitis

\begin{tabular}{lcc}
\hline Stage & Number & Percentage \\
\hline Early acute appendicitis & 30 & 85.71 \\
Suppurative appendicitis & 1 & 2.86 \\
Gangrenous appendix & 1 & 2.86 \\
Perforated appendix & 2 & 5.71 \\
Abscess & 1 & 2.86 \\
Total & 35 & 100 \\
\hline
\end{tabular}

clinical judgement because in few cases inflamed appendix could not be visualised due to bowel gases or is missed due to inexperience of ultrasonologist, hence positive USG as pre-requisite for appendicectomy will increase perforation rate leading to increased morbidity and mortality.

\section{Conclusion}

Inspite of low negative appendicectomy rate, which prevented many negative laparotomies and it's complications, combined use of modified Alvarado score and USG, in decision making for appendicectomy, has high sensitivity and accuracy, so that patients can be diagnosed in early acute appendicitis stage (Table 13), decreasing morbidity and postoperative complications.

\section{References}

1. Fitz RH (1886) Perforating inflammation of the vermiform appendix with special reference to it's early diagnosis and treatment. Am J Med Sci 92:321-346

2. Hobson T, Rosenman LD (1964) Acute appendicitis: when is it right to be wrong? Am J Surg 108:306-311

3. Kazarian KK, Roeder WJ, Mershcimer WL (1970) Decreasing



Fig. 5 Ultrasound showing (left) dilated appendix with $3.5 \mathrm{MHz}$ Probe, (right) dilated appendix of $12.5 \mathrm{~mm}$ diameter with $7.5 \mathrm{MHz}$ probe

mortality and increase morbidity from acute appendicitis. Am J Surg 119:681-685

4. Chang FC, Hogle HH, Welling DA (1974) The fate of the negative appendix. Am J Surg 126:752-754

5. Lewis FR, Hocolt JW, Bo-ey J (1975) Appendicits: a critical review of diagnosis and treatment in 1000 cases. Arch Surg 110:677-684

6. Jess P, Bjerregaard B, Brynitz S, Holst Christensen J, Kalaja E, Lund Kristenssen J (1981) Acute appendicitis prospective trial concerning diagnostic accuracy and complications. Am J Surg 141:232-234

7. Dunn EL, Moore EE, Elderling SC, Murphy JR (1982) The unnecessary laparotomy for appendicitis: can it be decreased? Am Surg 48:320-323

8. Bell MJ, Bower JRT, Ternberg JL (1982) Appendectomy in childhood: analysis of 105 negative exploration. Am J Surg 144:335-337

9. Berry J, Malt RA (1984) Appendicitis near its centenary. Ann Surg 200:567-755

10. Alvarado A (1986) A practical score for the early diagnosis of acute appendicitis. Ann Emerg Med 15:557-564

11. Teicher IRA, Landa B, Cohen M (1983) Scoring system to aid in diagnosis of appendicitis. Ann Surg 198:753-759

12. Lindberg G, Fenyo G (1988) Algorithmic diagnosis of appendicitis using Baye's theorem and logistic regression. In: Bayesian Statistics. 3rd edition, Bernardo JM, Degroot MH, Lindley DV, Smith AFM (Eds.) Proceedings of the third Valencia International Meeting Oxford: Clarendon Press 665-668

13. Ramirez JM, Dens J (1994) Practical score to aid decision making in doubtful cases of appendicitis. Br J Surg 81: 680-683

14. Gallego MG, Fadrique B, Nieto MA, (1998) Evaluation of ultrasonography and clinical diagnostic scoring in suspected appendicitis. Br J Surg 85:37-40

15. Owen TD, Williams H, Stiff G (1992) Evaluation of Alvarado score in acute appendicitis. J R Soc Med 85:87-88

16. Kalan M, Talbot IJ, Lunline WJ (1994) Evaluation to the modified Alvarado score in the diagnosis of acute appendicitis - a prospective study: Ann R Coll Surg Engl 76:418-419

17. Karstrup S, Torp-Pedersen S, Roikjaer O (1986) Ultrasonic 
visualization of the inflamed appendix. BR J Radiol 59: 985-986

18. Jeffery RB, Laing FC, Townsend RR (1988) Acute appendicitis: sonography criteria based on 250 cases. Radiology 167:321-329

19. Puylaert JB, Rutgers PH, Labisang RJ (1987) A prospective study of ultrasonography in the diagnosis of appendicitis. N Eng J Med 317:666-669

20. Abu-Yousef MM, Bleicher JJ, Maher JW, Urdaneta LF, . Franken EA Jr, Metcaff AM (1987) High-resolution sonography of acute appendicitis. AJR 149:53-58

21. Schwerk WB, Wichtrup B, Rothmund M, Ruschoff J (1989): Ultrasonography in the diagnosis of acute appendicitis: A prospective study. Gastroenterology 97: 630-639

22. Adams DH, Fine C, Brooke DC (1988) High resolution real time ultrasonography. A new tool in the diagnosis of acute appendicitis. Am J Surg 155:93-96

23. Kang WM, Lee CH, Chou YH, Lin HJ, Lo HC, Hu SC, P'eng FK (1989) A clinical evaluation of ultrasonography in the diagnosis of acute appendicitis. Surgery 105:154-159

24. Vignault F, Filiatrault D, Brandt ML, Garel L, Grigon A, Ouimet A (1990) Acute appendicitis in children: Evaluation with US. Radiology 176:501:504

25. Rioux M (1992) Sonographic detection of the normal and abnormal appendix. AJR 158:773-778

26. Crady SK, Jones JS, Wyn T, Luttenton CR (1993) Clinical validity of ultrasound in children with suspected appendicitis. Ann Emerg Med 22:1125-1129

27. John H, Neff U, Keleman M (1993) Appendicitis diagnosis today: clinical and ultrasonic deductions. World J Surg 17:243-49 